\title{
Comparison of methodologies to quantify the effects of age and area of marine reserves on the density and size of targeted species
}

\author{
Daniela Diaz Guisado ${ }^{1}$, Russell G. Cole ${ }^{2}$, Robert J. Davidson ${ }^{3}$, Debbie J. Freeman ${ }^{4}$, \\ Shane Kelly ${ }^{5}$, Alison Macdiarmid ${ }^{6}$, Anjali Pande ${ }^{1,7}$, Rob Stewart ${ }^{6}$, Carl Struthers ${ }^{1,8}$, \\ James J. Bell ${ }^{1}$, Jonathan P. A. Gardner ${ }^{1, *}$ \\ ${ }^{1}$ Centre for Marine Environmental \& Economic Research, School of Biological Sciences, Victoria University of Wellington, \\ Wellington 6140, New Zealand \\ ${ }^{2}$ National Institute of Water and Atmospheric Research (NIWA), Nelson 7010, New Zealand \\ ${ }^{3}$ Davidson Environmental Ltd, PO Box 958, Nelson 7040, New Zealand \\ ${ }^{4}$ Department of Conservation, Research and Development Group, Wellington 6143, New Zealand \\ ${ }^{5}$ Coastal and Aquatic Systems Ltd, Clevedon, Auckland 2248, New Zealand \\ ${ }^{6}$ National Institute of Water and Atmospheric Research (NIWA), Wellington 6021, New Zealand \\ ${ }^{7}$ Present address: Investigation and Diagnostic Centre, Biosecurity NZ, Ministry of Agriculture and Forestry, PO Box 40742 , \\ Wallaceville 0000, New Zealand \\ ${ }^{8}$ Present address: Museum of New Zealand Te Papa Tongarewa, Wellington 6011, New Zealand
}

\begin{abstract}
We quantified the biological response of 2 exploited species to marine reserve (MR) protection by comparing meta-analysis results based on response ratio (RR) and Hedges' $g$ statistics. To determine the effect of MR area and age on biological responses, a RR analysis was performed on density and size data for both species from sites inside versus outside 13 MRs. Most MRs supported a greater density of larger individuals than unprotected areas. Linear and non-linear plots of MR age and area with respect to species-specific density and size were used to quantify the trajectories of the responses. In the RR meta-analysis but not in the Hedges' $g$ meta-analysis, MR age explained significant variation in the density and size of both species, while no effect of MR area was detected in either analysis. Comparison of the performance of RR with that of Hedges' $g$ revealed no overall evidence of a relationship between them, probably because the RR does not include an estimate of variance, whereas the Hedges' $g$ analysis does. While RR analysis is an appropriate alternative to Hedges' $g$ statistic meta-analysis assessments of MR effectiveness because of its ease of use and interpretation, we recommend that future RR analyses include both an estimate of variance and a test for 'effect size'. Finally, we recommend that research be aimed at determining why different MRs produce different biological responses - that is, address why significant 'effect size' exists.
\end{abstract}

KEY WORDS: Response ratio $\cdot$ Meta-analysis $\cdot$ Marine conservation $\cdot$ Biological response $\cdot$ Marine management

Resale or republication not permitted without written consent of the publisher

\section{INTRODUCTION}

While no-take marine reserves (MRs) have become a highly advocated form of marine conservation, there is widespread recognition of the need to quantify the conservation benefits they provide (Allison et al. 1998, Halpern \& Warner 2002, Pande et al. 2008,
Botsford et al. 2009). Because MRs in different parts of the world are set up and managed for different purposes (e.g. fisheries enhancement, biodiversity protection, scientific research), the extent and direction of their biological outcomes may vary considerably. However, several recent reviews that have evaluated results from separate studies to quantify 
MR outcomes suggest that many species, especially those that are actively targeted by fisheries, increase in abundance and/or size inside MRs (Jones et al. 1992, Mosquera et al. 2000, Côté et al. 2001, Halpern \& Warner 2002, Halpern 2003, Lester et al. 2009, Pande et al. 2008).

The first MR in New Zealand (NZ) was created in 1975, and as of late 2011 there are 34 no-take MRs protecting $\sim 7.6 \%$ of NZ's territorial waters (New Zealand Department of Conservation http://doc. govt.nz/conservation/marine-and-coastal/marineprotecteted-areas). Partially or well-established ecological monitoring programmes exist in many of these MRs. However, despite a long lead-in time for the establishment of each MR, very few baseline data sets have been gathered to allow 'before versus after' comparisons. Such comparisons are a recommended measure for any restoration activity, because by sampling at one or more control sites and the impact site both before and after the intervention, they identify spatial and temporal variation (Osenberg et al. 1999). Due to the lack of baseline data, historical assessments of the efficacy of MRs are usually not possible (but see Pande \& Gardner 2009). Consequently, monitoring typically involves the comparison of sites inside MRs with non-MR 'control' sites (i.e. 'inside versus outside' comparisons). Although some monitoring results have shown increases in the mean size and/or mean density of some species at MR sites compared with unprotected sites, it is still difficult to assess the possible conservation benefits of MRs based on individual studies because the generality of response cannot be determined from single MRs (Kelly et al. 2000, Willans 2003, Pande et al. 2008, Davidson et al. 2009). Nonetheless, the aim of the NZ government is to protect $10 \%$ of the coastal marine environment via the establishment of Marine Protected Areas (MPAs, defined here as any form of protection and not just notake MRs) to assure the maintenance and/or recovery of biological diversity at the habitat and ecosystem level. A key component of this strategy is to monitor MPAs to assess their effectiveness at achieving biodiversity conservation objectives (Department of Conservation and Ministry of Fisheries 2005).

A variety of statistical approaches can be used to quantify MR effects. Commonly, meta-analysis is used to combine the results of multiple independent studies, all of which have tested the same hypothesis. This approach determines if enough evidence exists in the combined studies to detect an 'overall' outcome. This statistically rigorous approach moves beyond simple 'vote counting' or narrative review because it is a quantitative synthesis that allows for objective appraisal of the evidence (Arnqvist \& Wooster 1995, Egger et al. 1997, Osenberg et al. 1999). Perhaps because of its lack of familiarity to marine scientists or because of its statistical complexity (e.g. Berman \& Parker 2002), or because of the lack of accurate error estimates in the studies being reviewed, few meta-analyses of this type have been conducted for MRs or MPAs. However, those that have been conducted have reported that MRs support more and/or larger individuals of many species than neighbouring unprotected areas (e.g. Mosquera et al. 2000, Côté et al. 2001, Pande et al. 2008).

The most frequently employed effect-size metric in meta-analysis (Hedges' $g$ ) requires that variances, as well as means, are known, but in fact this is often not the case from published reports (Mosquera et al. 2000). From this information the magnitude and significance of an overall effect can be calculated across all studies. The overall effect size is calculated from the effect size of each individual study. An important step in this meta-analysis is the calculation of effectsize homogeneity across all studies. If the test fails, then the meta-analysis stops at this stage due to the significant difference among the effects that individual MRs have on the biological index because it is inappropriate to combine 'heterogeneous' data from the separate studies (e.g. Pande et al. 2008). An alternative approach to Hedges' statistic meta-analysis is the response ratio (RR) meta-analysis that has been used widely to describe the effects of MRs. This method does not require knowledge of variances because it quantifies the proportional change resulting from MR implementation by measuring the relative differences in a biological response (e.g. size or density) inside versus outside the MR (Adams et al. 1997, Goldberg et al. 1999, Hedges et al. 1999, Gates 2002). While it is possible to test RRs for homogeneity of responses analogous to the effect-size test described above (Mosquera et al. 2000), very few analyses employing RR do so.

Recent studies by Halpern \& Warner (2002), Halpern (2003), Micheli et al. (2004), Lester et al. (2009) and Molloy et al. (2009) all calculated RRs from multiple MRs worldwide to evaluate effects of protection on many invertebrate and fish species. They found consistent positive effects of MRs, suggesting that MRs achieve their stated or implicit conservation goals. Pande et al. (2008) employed the Hedges' $g$ index to assess the response of blue cod and rock lobster to full no-take MR protection in NZ. These authors also reported consistent positive effects of MRs. Importantly, both forms of metaanalysis demonstrate that marine protection can 
increase species abundance and size, particularly for species targeted by fishers. They also demonstrate that the response to MR protection may be independent of MR area and age, and it is usually dependent on the species being analysed. Despite the burgeoning publication of papers that use results from multiple studies to test hypotheses about biological change resulting from marine protection, there is presently no standard statistical approach for such studies. Having previously conducted a Hedges' statistic meta-analysis (Pande et al. 2008), we were keen to address this point.

The aim of the present study was twofold: (1) to compare the efficacy of the commonly used RR analysis against the less commonly used meta-analysis based on Hedges' $g$ to determine ease of use and comparability of results (compared to Pande et al. 2008); and (2) to quantify, using the RR analysis, the biological response of 2 heavily exploited species to MR protection along a north-south latitudinal gradient of $\sim 11$ degrees $(\sim 1250 \mathrm{~km})$ in New Zealand.

\section{METHODS}

Our analyses combined published and unpublished data from 13 New Zealand MRs (Fig. 1), each of which was sampled at different times over a maximum time period of $\sim 30 \mathrm{yr}$ (Table 1 ). We selected 2 widely distributed species in New Zealand for this analysis; blue cod Parapercis colias and rock lobster Jasus edwardsii. Both species are heavily exploited and have been monitored in a number of MRs. Comparable data for other NZ species do not exist. For both species, we extracted density (no. ind. $\mathrm{m}^{-2}$ ) and

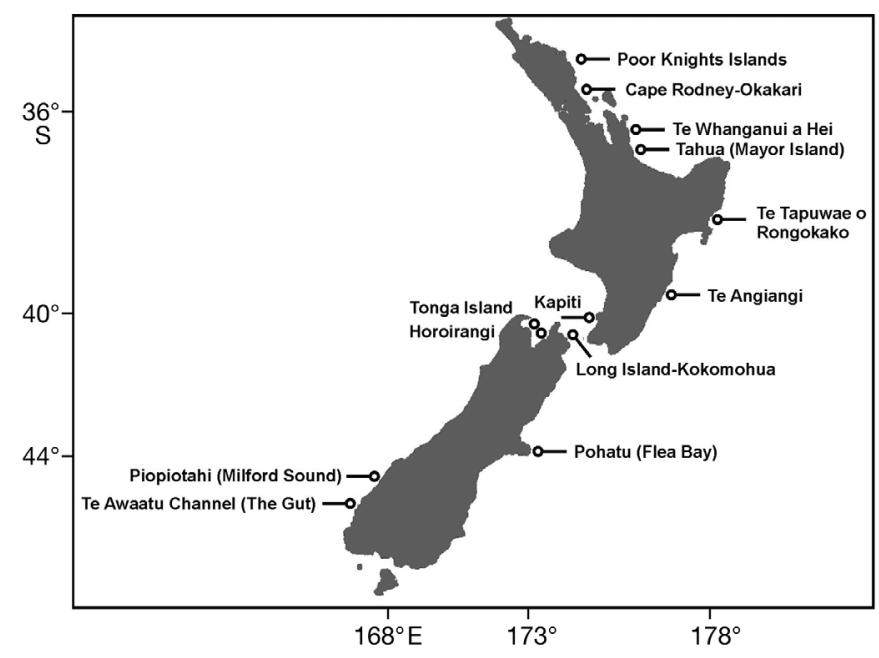

Fig. 1. Location of New Zealand marine reserves included in the response ratio (RR) analysis size $(\mathrm{cm})$ data from studies using only an Underwater Visual Census methodology (McCormick \& Choat 1987). The blue cod analysis used data from 8 MRs, including 20 separate studies (density: $8 \mathrm{MRs}$; size: 5 MRs). The rock lobster analysis used data from 13 MRs, including 24 separate studies (density: 13 MRs; size: $12 \mathrm{MRs}$ ): see Table 1 for details. All studies included measurements from inside MRs and from at least one control (fished) area outside the same reserve and in close proximity to it. This is the same data set used by Pande et al. (2008) for their Hedges' $g$ meta-analysis but with the addition of new survey periods and new sites (blue cod: 8 versus $5 \mathrm{MRs}$; rock lobster: 13 versus $10 \mathrm{MRs}$ ). All original studies included in our analyses were specifically conducted for the purposes of monitoring either blue cod or rock lobsters, and as such all were conducted in habitat appropriate for each taxon. We note that in an ideal world the MR sites will be the same in all respects as the nearby control sites. However, we also note that spillover from the MR into the control region may actually reduce the chance of seeing a significant difference between the MR(s) and the control(s). Thus, analyses of this type may tend to be conservative. However, the spillover effect may be counteracted by other factors, such as increased fishing effort in the control region (i.e. displacement of fishing activity from the MR to regions just outside). Thus, the spillover effect and the displaced fishing effort may balance out. Because of the absence of knowledge about site-specific spillover and displaced fishing activity, analytical consideration of such matters is not possible in any meta-analysis. While the number of sites surveyed, the duration (total no. of yr) of each study, and the timing of surveys all varied among studies, all studies were given equal weight in our analyses because there was no a priori reason to provide greater weight to any one study or group of studies than to the rest.

Consistent with their use elsewhere (e.g. Halpern \& Warner 2002, Halpern 2003, Lester et al. 2009), response ratios (RRs) were calculated by dividing values of mean density or mean size inside the reserve by values from control sites. RRs $>1$ indicate individuals are bigger or more abundant inside reserves relative to control sites. RRs are site-specific and therefore reflect local conditions. For example, where increased growth rates of blue cod in colder waters may be expected, this will be true of the coldwater MR site and its neighbouring fished site. Thus, the RR calculated for this site may be compared directly with the RR calculated from a northern, warm water site because both tell us about the mag- 
Table 1. Marine reserve variables (area, year of establishment, age) and species-specific data sets used in the analysis

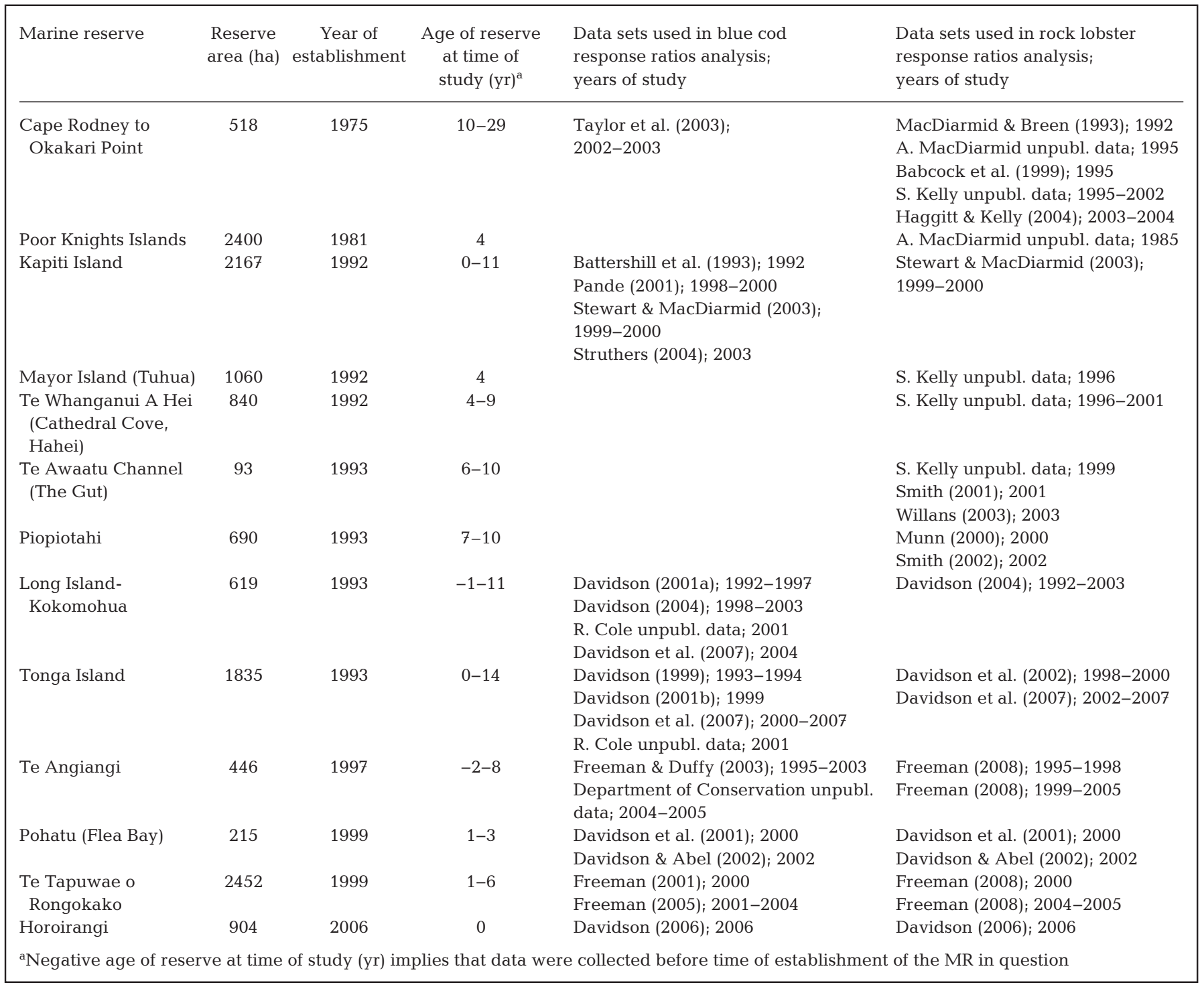

nitude of the local response. However, the RR values do not provide information about actual fish size or density inside versus outside the MR, or about actual fish size or density when comparing between cold and warm sites. From this survey data, with associated RR values for each year of each survey, we generated 2 separate data sets for statistical analysis, as described below.

First, for all data sets (blue cod size and density, rock lobster size and density) we identified the single most recent survey regardless of its date (and its associated RR value) per site. We call this the $R_{\text {recent }}$ data set because it contains a single value per marine reserve based on only the most recent survey. This approach gives no weighting or consideration to ear- lier survey data-that is, the history of change is not considered-with the result that the data set may be strongly influenced by one unusual data point for any one MR.

Second, for all data sets individual RR values were calculated for each year of each survey for each MR. The strength of this approach is that individual MRs contributed many year-specific data points reflecting their history of change. The weakness is that such data points are not independent in a statistical sense. Non-independence of data in meta-analyses may be a problem (e.g. Mosquera et al. 2000, Gates 2002, Pande et al. 2008), and for this approach many of the points within this data set are not independent. Nonetheless, this approach is informative and we 
employ it here to better understand the responses of blue cod and rock lobster to protection and the effect of MR age and size on these species. We call this approach $\mathrm{RR}_{\max }$ because it provides the maximum number of data points per analysis. For only the $\mathrm{RR}_{\max }$ analyses we separated the MRs into 2 groups to test specific patterns, where size of the data set permitted. Based on area we recognised small and large MRs ( $\leq$ or $>1000$ ha), whilst based on age we recognised young and old reserves $(\leq$ or $>10 \mathrm{yr}$ ). While these distinctions are somewhat arbitrary there is some theoretical underpinning to support these cut off points in terms of the average area and age of NZ MRs, the rate of biological response recorded from various regions, and the life history characteristics of the species in question (Halpern \& Warner 2002, Halpern 2003, Micheli et al. 2004, Pande et al. 2008, Lester et al. 2009, Molloy et al. 2009). Importantly the divisions at $10 \mathrm{yr}$ and 1000 ha allow for sufficient data points for analysis of young versus old and small versus large data sets, and minimise the bias caused by having data from only 1 or 2 older (larger) and well monitored MRs.

The 2 RR indices are appropriate for answering different questions and their applicability depends on the type of data available. $R_{\text {recent }}$ is appropriate for assessment of overall reserve effect, whereas $R R_{\max }$ is appropriate for assessment of temporal changes within reserves. Because we are interested in both aspects (overall reserve effect on blue cod and rock lobsters and temporal change), we employ both indices here.

Following Mosquera et al. (2000), we tested to determine if all biological responses were homogeneous using the homogeneity statistic of Hedges \& Olkin (1985). In all instances, the test statistic was non-significant ( $p>0.05)$, indicating that each data set was homogeneous, and that no single MR had an undue effect.

To evaluate the effects of MR area and age on biological response for both data sets, $R R$ values were plotted against MR area (ha) and age (yr) (Table 1). Linear and non-linear functions were fitted to species-specific plots to determine the best fits based on correlation coefficient values (SlideWrite Plus v.3, Advanced Graphics). This approach permits the identification of the best-fit relationship without a priori knowledge of the trajectory of the relationship being examined, or without imposing assumptions about the nature of the response. We used this approach as an exploratory tool to see if a pattern exists within our data that may help us to better understand the generalised trajectory of response for the 2 different species. As a third and final approach to better understand the relationships between $\mathrm{RR}$ and MR age and MR area for both data sets, we employed the Spearman's rank correlation analysis (1-tailed tests) to test the statistical basis of the linear relationship between RR and MR area and age. We employed this analysis because it is a non-parametric (rank) test of a linear relationship with minimal assumptions about data distribution. This analysis was conducted using the Statistica software (v7.1 StatSoft Software). In all cases where fitted lines/curves were highly leveraged by a single point, we removed that point from the data set and re-fitted the line/curve to re-test for significance. Finally, to compare directly between the RR and Hedges' approaches, we plotted $R_{\text {recent }}$ against Hedges' $g$ for all comparisons where such data exist. We used Pearson's correlation coefficient to test for a linear relationship between the 2 different indices.

\section{RESULTS}

In most instances the values for both RR indices for both species were $>1.0$, indicating greater mean size or density inside the MR than outside $\left(R_{\text {recent }}\right.$ Fig. 2; $\mathrm{RR}_{\max }$ : Fig. 3). Spearman's rank correlation analyses are presented as rank-rank plots. Because of the different number of data points per analysis (see degrees of freedom columns, Tables $2 \& 3$ ) the 2 RR indices have different powers to detect significance.

\section{$\mathbf{R R}_{\text {recent }}$ analyses for blue cod}

The relationship between blue cod density and MR age was statistically significant (Fig. 2B, Table 2) for all 3 tests. The best fit was observed for the nonlinear model, but the 2 linear models both had $\mathrm{R}$ values similar to that reported for the non-linear model. Removal of one outlier (data point at $28 \mathrm{yr}$ ) removed the significant nature of the relationship for both the parametric and non-parametric linear fits, but increased the significance of the non-linear fit. All other analyses of $\mathrm{RR}_{\text {recent }}$ were not statistically significant (Table 2).

\section{$\mathbf{R R}_{\text {max }}$ analyses for blue cod}

There was a statistically significant positive relationship between MR age and the density (Fig. 3B) 

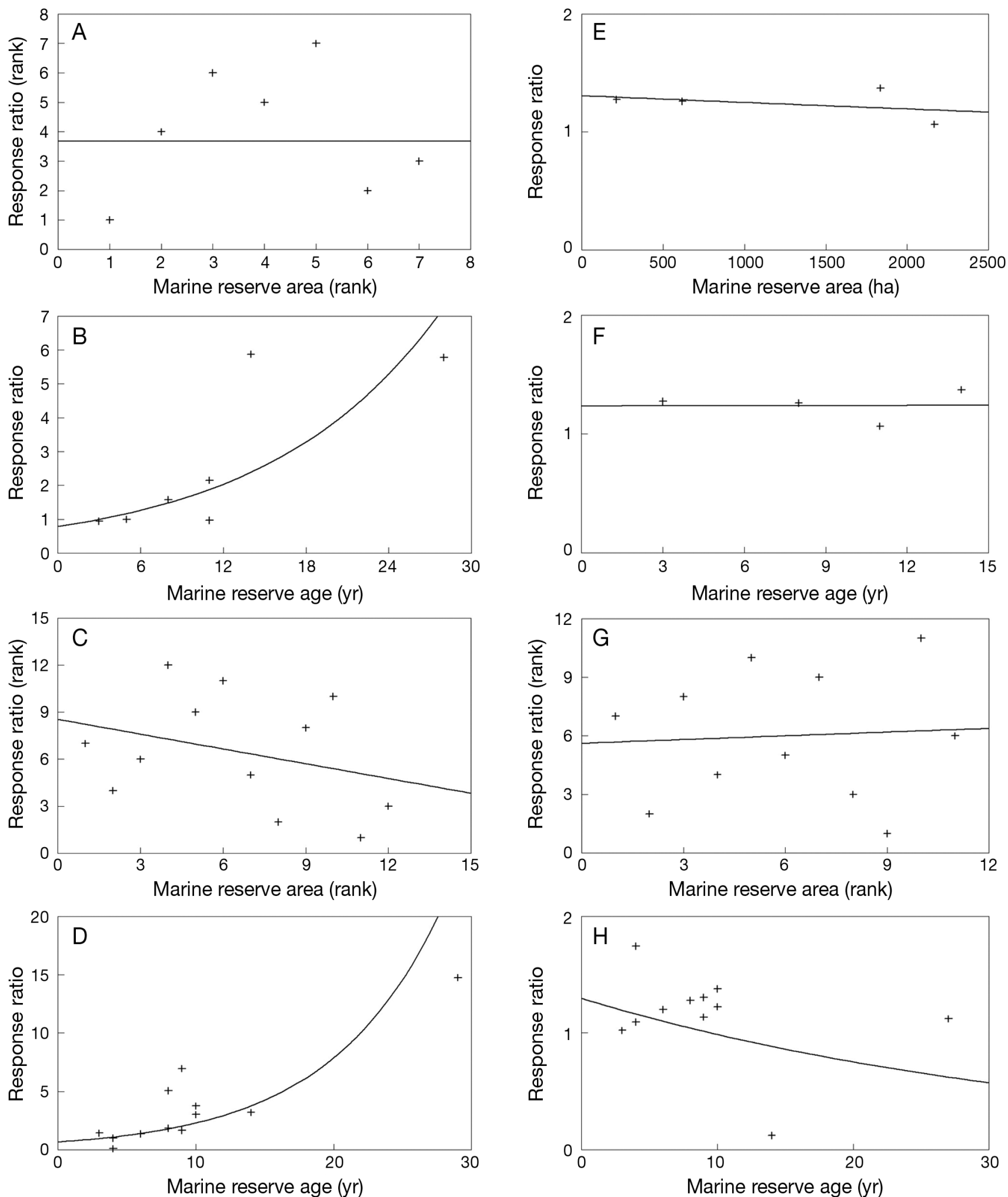

Fig. 2. Best-fit relationship for the scatter plot of response ratio values $\left(R_{\text {recent }}\right)$ as a function of marine reserve (MR) area and $\mathrm{MR}$ age. $\mathrm{RR}_{\text {recent }}$ is calculated from the single most recent survey, regardless of how many previous surveys have been conducted, at any one site. (A) Blue cod density as a function MR area ( $>0.05)$ and (B) age (p < 0.05). (C) Rock lobster density as a function of MR area $(p>0.05)$ and $(D)$ age $(p<0.05)$. (E) Blue cod size as a function of MR area $(p>0.05)$ and $(F)$ MR age $(p>0.05) .(G)$ Rock lobster size as a function of MR area $(p>0.05)$ and $(H)$ age $(p>0.05)$ 

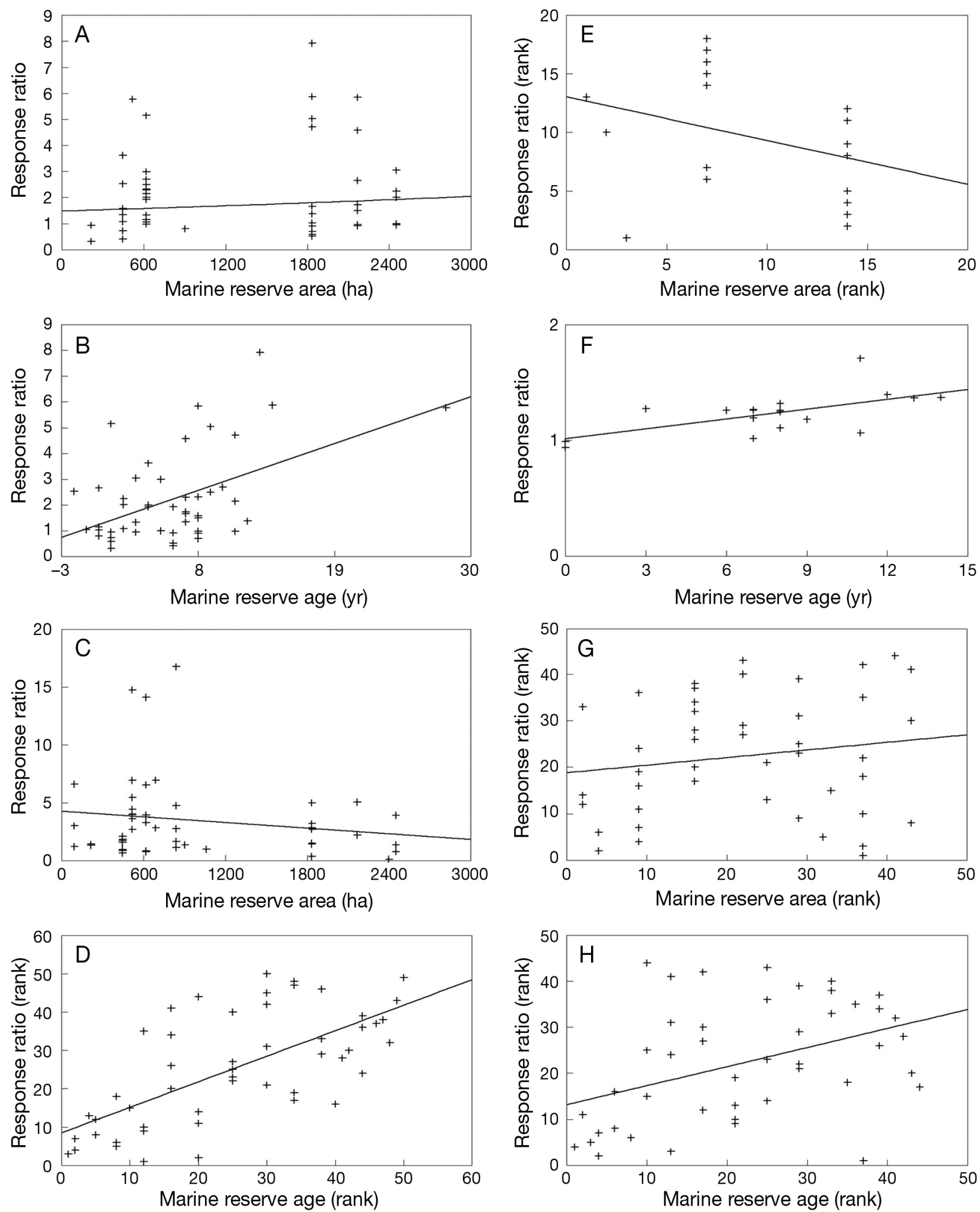

Fig. 3. Best-fit relationship for the scatter plot of response ratio values $\left(R_{\max }\right)$ as a function of marine reserve (MR) area and $M R$ age. $R R_{\max }$ is calculated as an average value across all surveys that have been conducted for any one site. (A) Blue cod density as a function of MR area ( $p>0.05)$ and (B) MR age $(p<0.001)$. (C) Rock lobster density as a function of MR area ( $>$ $0.05)$ and (D) MR age $(p<0.001)$. (E) Blue cod size as a function of MR area (p > 0.05) and (F) MR age (p<0.01). (G) Rock lobster size as a function of MR area $(p>0.05)$ and $(H)$ MR age $(p<0.01)$ 
Table 2. Test results (linear and non-linear functions plus Spearman's rank correlation analysis) for the response ratio (RR $\mathrm{R}_{\mathrm{recent}}$ see Fig. 2) for blue cod (BC) and rock lobster (RL) density and size with respect to marine reserve (MR) area and age. Bold values are significant at $\mathrm{p}<0.05$; ns: not significant

\begin{tabular}{|c|c|c|c|c|c|c|c|}
\hline \multirow{3}{*}{$\begin{array}{l}\text { Index }\left(\mathrm{RR}_{\text {recent }}\right) \\
\text { (Figure reference) }\end{array}$} & \multirow[t]{3}{*}{$\mathrm{df}$} & \multicolumn{4}{|c|}{ Best-fit relationship analyses } & \multirow{2}{*}{\multicolumn{2}{|c|}{$\begin{array}{l}\text { Spearman's rank } \\
\text { correlation results }\end{array}$}} \\
\hline & & \multicolumn{2}{|c|}{ Linear model } & \multicolumn{2}{|c|}{ Non-linear model } & & \\
\hline & & $\mathrm{R}$ & $\mathrm{p}$ & $\mathrm{R}$ & $\mathrm{p}$ & $\mathrm{R}$ & $\mathrm{p}$ \\
\hline BC density vs. MR area (Fig. 2A) & 5 & -0.079 & ns & -0.033 & ns & 0.107 & ns \\
\hline \multirow[t]{2}{*}{ BC density vs. MR age (Fig. 2B) } & 5 & 0.813 & $<0.05$ & 0.822 & $<0.05$ & 0.811 & $<0.05$ \\
\hline & $4^{\mathrm{a}}$ & 0.722 & ns & 0.980 & $<0.001$ & 0.754 & ns \\
\hline BC size vs. MR area (Fig. 2E) & 2 & -0.363 & ns & -0.813 & ns & -0.400 & ns \\
\hline BC size vs. MR age (Fig. 2F) & 2 & 0.045 & ns & 0.616 & ns & 0.200 & ns \\
\hline RL density vs. MR area (Fig. 2C) & 10 & -0.264 & ns & -0.315 & ns & -0.315 & ns \\
\hline \multirow[t]{2}{*}{ RL density vs. MR age (Fig. 2D) } & 10 & 0.900 & $<0.001$ & 0.910 & $<0.001$ & 0.787 & $<0.05$ \\
\hline & $9^{\mathrm{a}}$ & 0.543 & ns & 0.548 & ns & 0.693 & $<0.05$ \\
\hline RL size vs. MR area (Fig. 2G) & 9 & -0.0268 & ns & $<0.001$ & ns & 0.0636 & ns \\
\hline \multirow[t]{2}{*}{ RL size vs. MR age (Fig. 2H) } & 9 & -0.289 & ns & -0.353 & ns & -0.050 & ns \\
\hline & $8^{\mathrm{a}}$ & -0.552 & ns & -0.871 & $<0.01$ & 0.031 & ns \\
\hline
\end{tabular}

Table 3. Test results (linear and non-linear functions plus Spearman's rank correlation analysis) for the response ratio (RR $\mathrm{max}_{\mathrm{i}}$ see Fig. 3) of blue cod (BC) and rock lobster (RL) density and size with respect to marine reserve (MR) area (small [ $\leq 1000$ ha] and large [ $>1000 \mathrm{ha}]$ ) and age (young [ $\leq 10 \mathrm{yr}]$ and old [ $>10 \mathrm{yr}]$ ). Bold values are significant at $\mathrm{p}<0.05$; ns: not significant

\begin{tabular}{|c|c|c|c|c|c|c|c|}
\hline \multirow{3}{*}{$\begin{array}{l}\text { Index }\left(\mathrm{RR}_{\max }\right) \\
\text { (Figure reference) }\end{array}$} & \multirow[t]{3}{*}{ df } & \multicolumn{4}{|c|}{ Best-fit relationship analyses } & \multirow{2}{*}{\multicolumn{2}{|c|}{$\begin{array}{l}\text { Spearman's rank } \\
\text { correlation results }\end{array}$}} \\
\hline & & \multicolumn{2}{|c|}{ Linear model } & \multicolumn{2}{|c|}{ Non-linear model } & & \\
\hline & & $\mathrm{R}$ & $\mathrm{p}$ & $\mathrm{R}$ & $\mathrm{p}$ & $\mathrm{R}$ & $\mathrm{p}$ \\
\hline BC density vs. MR area (Fig. 3A) & 47 & 0.123 & ns & 0.221 & ns & 0.106 & ns \\
\hline MR area, small reserves (Fig. 4A) & 23 & 0.179 & ns & 0.318 & ns & 0.258 & ns \\
\hline MR area, large reserves (Fig. 4F) & 22 & -0.163 & ns & $<-0.001$ & ns & 0.079 & ns \\
\hline MR age (Fig. 3B) & 47 & 0.487 & $<0.001$ & 0.487 & $<0.001$ & 0.351 & $<0.02$ \\
\hline BC size vs. MR area (Fig. 3E) & 16 & $<-0.001$ & ns & -0.077 & ns & -0.345 & ns \\
\hline MR age (Fig. 3F) & 16 & 0.617 & $<0.01$ & 0.617 & $<0.01$ & 0.564 & $<0.02$ \\
\hline RL density vs. MR area (Fig. 3C) & 48 & -0.167 & ns & -0.167 & ns & -0.055 & ns \\
\hline MR area, small reserves (Fig. 4B) & 34 & 0.191 & ns & 0.191 & ns & 0.231 & ns \\
\hline MR area, large reserves (Fig. 4G) & 12 & 0.033 & ns & -0.206 & ns & -0.064 & ns \\
\hline MR age (Fig. 3D) & 48 & 0.412 & $<0.01$ & 0.434 & $<0.01$ & 0.665 & $<0.001$ \\
\hline MR age, young reserves (Fig. 4C) & 37 & 0.490 & 0.001 & 0.500 & $<0.001$ & 0.693 & $<0.05$ \\
\hline MR age, old reserves (Fig. 4H) & 9 & 0.653 & $<0.05$ & 0.883 & $<0.001$ & 0.798 & $<0.01$ \\
\hline RL size vs. MR area (Fig. 3G) & 42 & 0.086 & ns & $<0.001$ & ns & 0.162 & ns \\
\hline MR area, small reserves (Fig. 4D) & 30 & 0.199 & ns & 0.247 & ns & 0.282 & ns \\
\hline MR area, large reserves (Fig. 4I) & 10 & 0.302 & ns & 0.369 & ns & 0.291 & ns \\
\hline MR age (Fig. 3H) & 42 & 0.084 & $\mathrm{~ns}$ & $<0.001$ & ns & 0.414 & $<0.01$ \\
\hline MR age, young reserves (Fig. 4E) & 32 & 0.444 & $<0.02$ & 0.466 & $<0.01$ & 0.549 & $<0.001$ \\
\hline MR age, old reserves (Fig. $4 \mathrm{~J}$ ) & 8 & 0.312 & ns & 0.316 & ns & -0.129 & ns \\
\hline
\end{tabular}

and size (Fig. 3F) of blue cod (Table 3). In both cases there was no difference (to 3 decimal places) between the correlation coefficients for the linear and non-linear (exponential) relationships. MR area did not explain variation in RRs for either the density or size of blue cod in any of the 3 separate analyses (Figs. 3 \& 4, Table 3). Because of small sample sizes, we were unable to test the blue cod data for the effect of MR age young ( $\leq 10 \mathrm{yr}$ ) versus old (>10 yr).
Fig. 4. Best-fit relationship for the scatter plot of response ratio values ( $R R_{\max }$, see Fig. 3) as a function of marine reserve (MR) area for small and large reserves and as a function of MR age for young and old reserves (see Table 3). (A) Blue cod density as a function of MR area for small ( $p>0.05)$ and $(F)$ large reserves ( $p>0.05)$. (B) Rock lobster density as a function of $M R$ area for small ( $p>0.05)$ and $(G)$ large reserves $(p>0.05)$. (C) Rock lobster density as a function of MR age for young $(\mathrm{p}<$ $0.001)$ and $(\mathrm{H})$ old reserves $(\mathrm{p}<0.001)$. (D) Rock lobster size as a function of MR area for small ( $p>0.05$ ) and (I) large reserves ( $p>0.05$ ). (E) Rock lobster size as a function of MR age for young $(p<0.001)$ and $(J)$ old reserves $(p>0.05)$ 

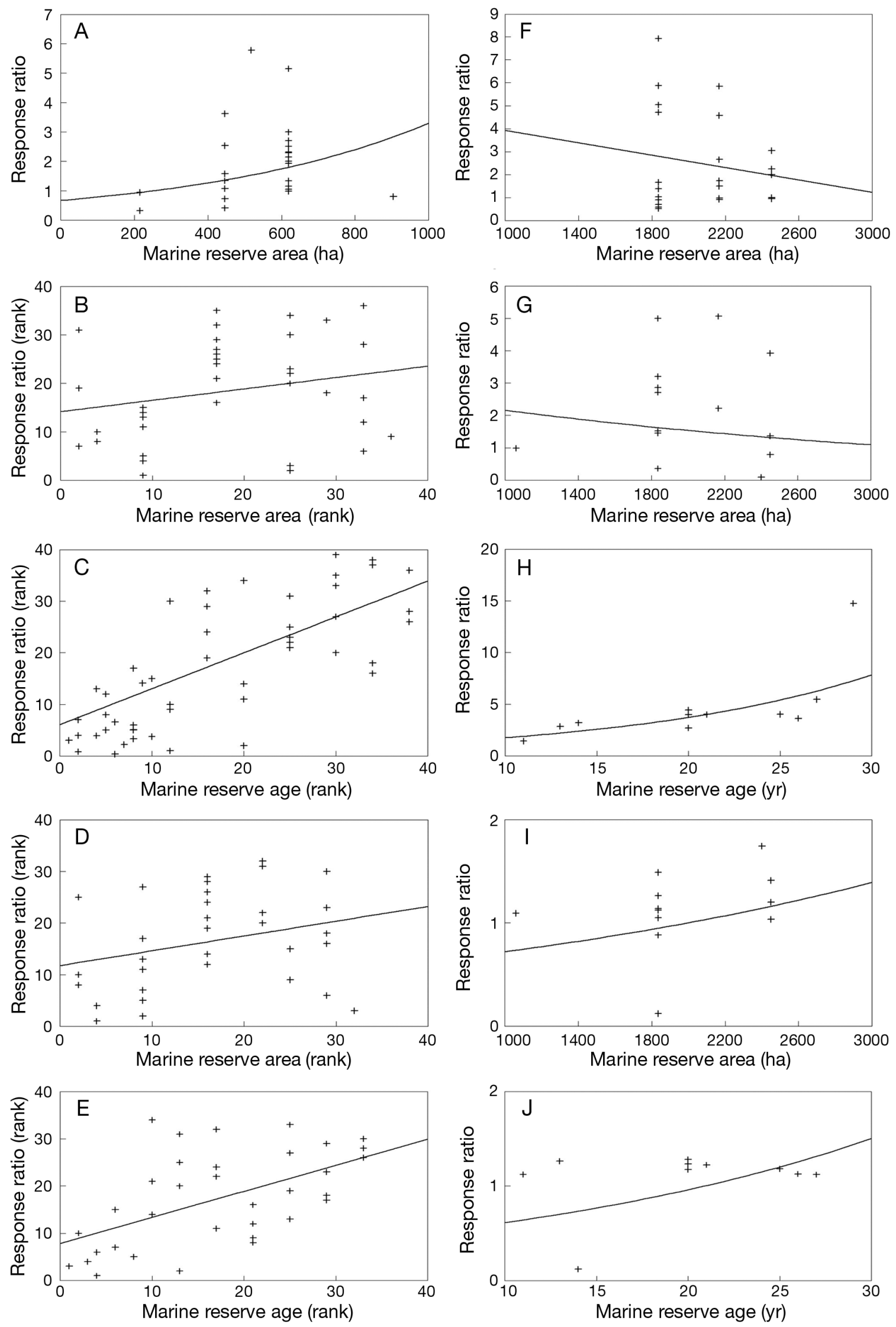


\section{$\mathbf{R R}_{\text {recent }}$ analyses for rock lobster}

Statistically significant results for all 3 analyses were observed for rock lobster density and MR age (Fig. 2D, Table 3). The best fit was for the non-linear model, but the linear parametric model had only a slightly lower R value. Dropping one outlier from this analysis resulted in only the Spearman's rank correlation being statistically significant. The only other statistically significant model was the non-linear fit for rock lobster size and MR age: this relationship was negative and only significant after an outlier had been dropped (Fig. 2H, Table 3).

\section{$\mathbf{R R}_{\max }$ analyses for rock lobster}

There was a statistically significant positive relationship between MR age and rock lobster density (best fit = linear rank relationship; Fig. 3D) and between MR age and rock lobster size (best fit = linear rank relationship; Fig. 3H, Table 3). In young MRs, the best fit was a linear rank relationship with rock lobster density (Fig. 4C), whereas in old MRs the best fit was an exponential relationship with density (Fig. 4H). For rock lobster size, the best fit relation- ship with MR age among young reserves was a linear rank relationship (Fig. 4E), whilst the relationship between MR age and rock lobster size for old reserves was not significant (Fig. 4J, Table 3). MR area did not explain variation in rock lobster size or density estimates inside versus outside the reserves in any of the analyses (Figs. $3 \& 4$, Table 3).

\section{Comparison of $\mathbf{R} R_{\text {recent }}$ versus Hedges' $g$ statistics}

Plots of Hedges' $g$ statistic as a function of $\mathrm{RR}_{\text {recent }}$ revealed no obvious linear relationship for the blue cod density data set $(n=5, p=0.489$, Fig. $5 a$ ) or for the rock lobster size data set $(n=8, p=0.069$, Fig. $5 d)$, but did reveal significant linear relationships for the blue cod size data set $(n=4, p=0.048$, Fig. 5b) and for the rock lobster density data set $(n=10, p=0.043$, Fig. $5 c)$. When all the data was pooled and plotted, we observed a non-statistically significant positive relationship ( $\mathrm{n}=27, \mathrm{p}=0.206$, Fig. 6a) that was heavily influenced by a single point. When we removed this point (for rock lobster density from the Cape Rodney to Okakari Point MR) we observed a non-statistically significant negative relationship ( $\mathrm{n}=26, \mathrm{p}=0.212$, Fig. 6b) between $\mathrm{RR}_{\text {recent }}$ and Hedges' $g$ statistic.

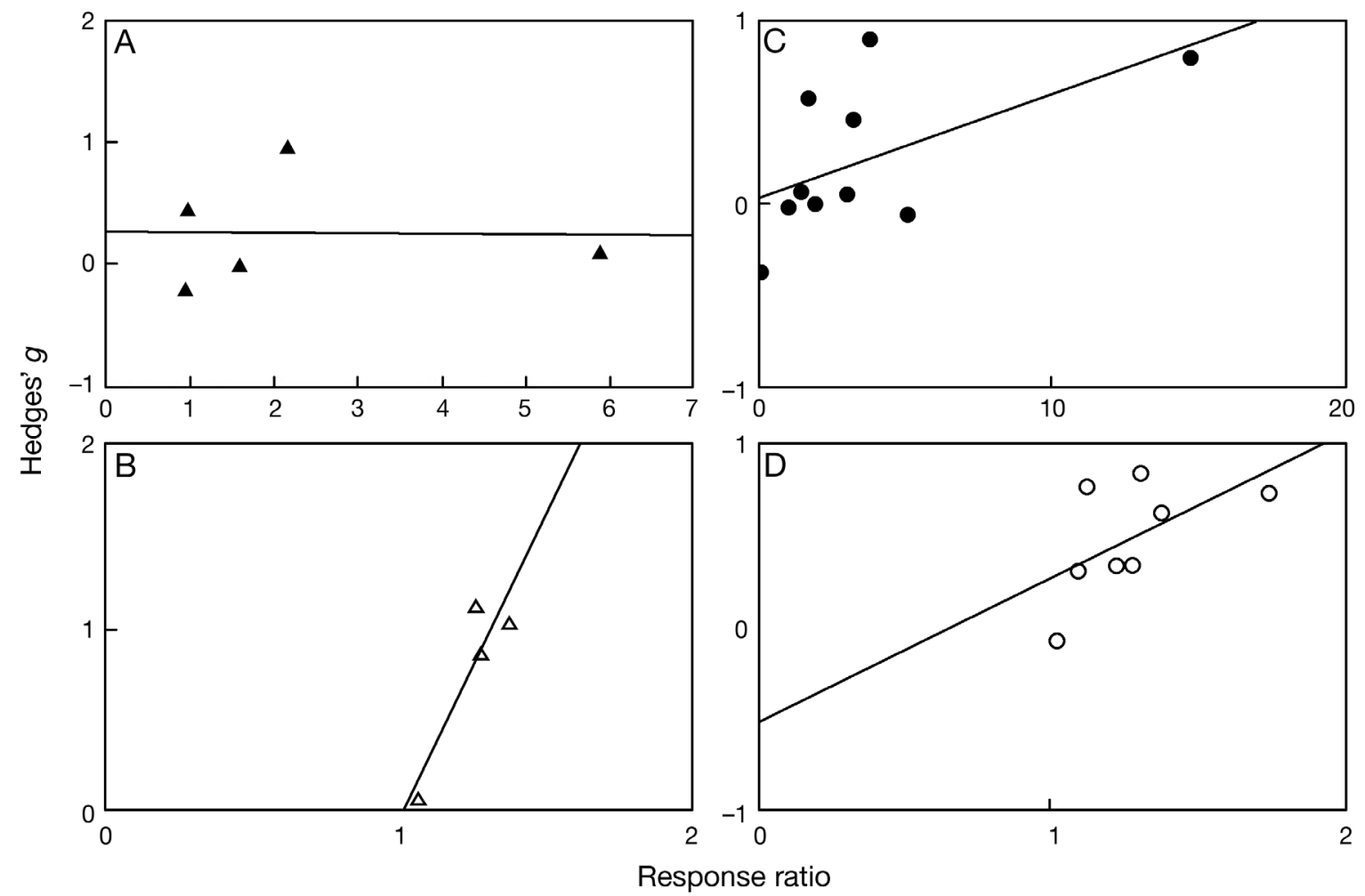

Fig. 5. Species-specific relationships between response ratio values $\left(R_{\text {recent, }}\right.$ see Fig. 2$)$ and Hedges' $g$ statistic for (A) blue cod density data $(\mathrm{n}=5)$, (B) blue cod size data $(\mathrm{n}=4)$, $(\mathrm{C})$ rock lobster density $(\mathrm{n}=10)$, and $(\mathrm{D})$ rock lobster size data $(\mathrm{n}=8)$ 


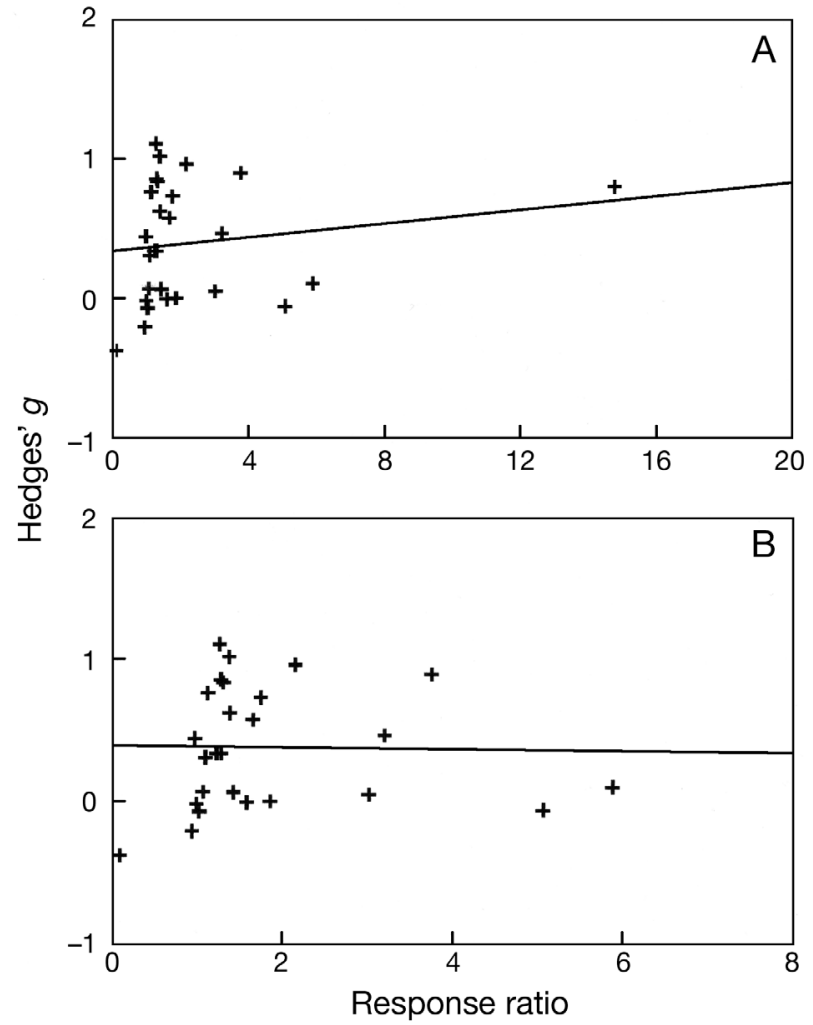

Fig. 6. Hedges' $g$ statistic as a function of response ratio values $\left(R_{\text {recent, }}\right.$ see Fig. 2) for $(A)$ all data $(n=27)$ and $(B)$ all data with a single heavily weighted point for rock lobster density at the Cape Rodney to Okakari Point Marine Reserve removed $(n=26)$

\section{DISCUSSION}

The main intention of the present study is to compare the RR approach with the Hedges' statistic meta-analysis approach to quantifying biological responses in marine reserves using NZ examples. In addition, we are interested in determining how MR age and area affect the biological responses of these 2 targeted species. To do this, we highlight the novel findings from this RR analysis and contrast these with the findings from the Hedges' $g$ meta-analysis (Pande et al. 2008).

\section{Effects of MRs on the density and size of individuals}

As expected, our results indicate positive effects of MRs on the density and size of both blue cod and rock lobster. We obtained RR values $>1$ for almost all MRs used in the analysis (the 4 exceptions were Pohatu, Horoirangi, Poor Knights Islands, and Mayor Island). For these reserves, we had little data (only 1 or 2 yr), or data only existed for 1 yr after reserve establishment. In contrast, all the RRs calculated for Cape Rodney to Okakari Point MR (the oldest MR in New Zealand) were $>1$. Data for this reserve included several studies performed by different investigators from 10 to $29 \mathrm{yr}$ after establishment. Based on the RR values, the biological responses that we observed for both species were greater for density than for size, and were generally, but not consistently, greater for rock lobster than for blue cod. Overall, and consistent with other studies (e.g. Mosquera et al. 2000, Côté et al. 2001, Halpern \& Warner 2002, Halpern 2003, Pande et al. 2008, Lester et al. 2009), our results demonstrate that MRs produce positive increases in the density and size of species that are heavily targeted for recreational, customary, and/or commercial harvesting.

\section{Effect of MR area on biological response}

Previous studies indicate that MR area may not always influence the biological response to MR protection (e.g. Côté et al. 2001, Halpern \& Warner 2002, Halpern 2003, Guidetti \& Sala 2007, Pande et al. 2008, but see Claudet et al. 2008 for counter example). Theoretical studies suggest that larger MRs should be more effective than smaller MRs, mainly because larger reserves allow more mobile species with wide home ranges to remain protected inside reserves. This is because larger MRs tend to have increased area to boundary ratios and because they may also increase self-recruitment by protecting areas of settlement for larvae produced inside reserves (Botsford et al. 2003, Hastings \& Botsford 2003, Roberts et al. 2003). Despite this, most evidence demonstrates that when a MR is established the biological response is rapid and occurs independently of MR area (Halpern \& Warner 2002, Halpern 2003, Micheli et al. 2004), at least over the range of MR sizes and species so far considered (e.g. see Cole et al. 1990).

All of our analyses revealed no effect of MR area on the density or size of blue cod and rock lobster across a wide range of $\mathrm{MR}$ sizes (for blue cod MR size range was 215 to $2452 \mathrm{ha}$, mean size $=1144.5 \mathrm{ha}$; for rock lobster MR size range was 93 to 2452 ha, mean size = 1095.3 ha). These results indicate that biological response is independent of MR area and suggest that small reserves function as well as large reserves for these species. While it is encouraging from a conservation perspective to think that small reserves can produce meaningful conservation outcomes (at least for some species), the apparent absence of a relationship between biological response and $\mathrm{MR}$ area is 
notable given the importance of habitat area in other studies (e.g. Claudet et al. 2008) and the fact that theoretical studies indicate that large MRs should be more effective for conservation than small MRs (e.g. Botsford et al. 2003, Hastings \& Botsford 2003, Roberts et al. 2003). Our result is surprising given that species such as blue cod and rock lobster are not highly vagile, although they do display some movement ability (Davidson 2001a, Kelly 2001, Kelly \& MacDiarmid 2003, Struthers 2004). As such they are expected to benefit from MR protection, and larger areas are, on average, expected to protect more individuals (Pande et al. 2008, Pande \& Gardner 2009). The result may be explained by features or properties that are specific to each MR. For example, the effect of protection in each individual reserve may be determined by many local factors other than just the area (size) of the reserve. These may include reserve location, site-specific coastal oceanography, physical complexity and habitat quality, and extent and distribution (Freeman et al. 2009). The latter 2 factors are very difficult to evaluate and are likely to be independent of reserve area, but nonetheless are expected to contribute substantially to the biological responses observed in each MR (Halpern \& Warner 2003, Guidetti \& Sala 2007). Finally, we note that enforcement (policing of the no-take areas) has been identified as being a key factor contributing to MR success (e.g. Samoilys et al. 2007). Because no data exist about levels of illegal extractive use or about enforcement differences across the MRs studied here, we are not in a position to know if or how this factor may have contributed to our study. However, based on anecdotal information from the NZ Department of Conservation and our own experience, we do not believe that differences in enforcement explain the results that we report here.

\section{Effect of MR age on biological response}

All analyses revealed the importance of MR age as a factor explaining positive biological responses. Reserve age is usually considered to be an important factor in MR effectiveness, because the response of individuals to protection is thought to depend upon the relationship between life-history traits of the species protected and the duration of protection (Guidetti \& Sala 2007, Molloy et al. 2009). Increases in size and/or density of target species may be expected for a number of different reasons, including increased protection (no extractive use), increased recruitment to the MR itself (recruitment to the MR of offspring derived from adults in the MR or recruitment to the MR from outside the MR), decreased natural mortality of the target species inside the MR as a consequence of ecosystem changes arising from protection, and the mobility of the species in question. Perhaps not surprisingly, different species react to MR status in different ways and at different rates. For example, decadal-scale indirect effects on taxa that occur as a consequence of cascading trophic interactions take longer to develop than direct effects on target species (Babcock et al. 2010).

Evidence indicates that a new reserve results in a rapid and significant increase in average levels of density, biomass, and diversity within 1 to 3 yr before the response slows down or stabilises (e.g. Halpern \& Warner 2002, Halpern 2003, Micheli et al. 2004). However, a recent meta-analysis of the response of fish populations to MR protection determined that older reserves $(>15 \mathrm{yr}$ ) are more effective than younger reserves $(\leq 15 \mathrm{yr})$ at increasing fish densities, indicating that $\mathrm{MR}$ age is an important factor explaining biological response (Molloy et al. 2009). Our results demonstrate that MR age has a strong positive effect on the biological responses of blue cod and rock lobster. For the $\mathrm{RR}_{\text {recent }}$ analyses we observed a strong positive effect of MR age on blue cod and rock lobster density but not size, despite the fact that most RR values for size for both species were $>1.0$, indicating larger individuals exist inside versus outside the MR. For the $\mathrm{RR}_{\max }$ approach, our results demonstrate that MR age has a strong positive effect on the density and size of blue cod and the density of rock lobster. We found evidence of significant positive relationships for all analyses except for that between rock lobster size and old (>10 yr) reserves. The findings indicate that both species respond rapidly to protection, with $\mathrm{RR}$ values $>1$ being recorded in the first few years after MR designation, consistent with estimates of species-specific growth rates and also density-dependent responses (e.g. Cole et al. 2000, Davidson 2001a, Davidson et al. 2002, Freeman 2008 and references therein). When analysed as a function of time, the best-fit response in all cases was linear. The association between rock lobster density and MR age for young reserves was best described by a linear relationship, whereas that for old reserves was best described by a nonlinear relationship (despite a small sample size for this latter analysis we observed $\mathrm{p}<0.001$ ). This difference in age-dependent response may reflect density-dependent factors, as rock lobsters increase in density towards site-specific carrying capacity. The association between rock lobster size and MR 
age for young reserves was linear and strongly positive, but was not significant among the old reserves. These results suggest that rock lobster size can respond rapidly and positively after MRs are declared, but after $\sim 10$ yr the response becomes independent of MR age. This may reflect the biological ability of rock lobsters to grow to larger sizes as a rapid response to MR protection, but after $10 \mathrm{yr}$ such a response is no longer possible because a growth response plateau has been achieved. Thus, in terms of size response, the notable changes occur rapidly, but plateau (reach an asymptote) after $10 \mathrm{yr}$.

\section{Use of RR indices and curve fitting}

Response ratios (RR) may easily be calculated in different ways, as demonstrated by our use of $R R_{\text {recent }}$ and $R_{\max }$. Despite the different origins of the $2 R R$ indices $\left(R R_{\text {recent }}\right.$ t the most recent survey only; $R_{\max }$ : an average value calculated from all surveys) and also their different properties $\left(\mathrm{RR}_{\text {recent }}\right.$ independence of data points; $\mathrm{RR}_{\max }$ : non-independence of points leading to pseudo-replication), both tended to give very similar results. $\mathrm{RR}_{\text {recent }}$ was surprisingly informative given its limited power to detect significance (low degrees of freedom because one RR value per study). We employed 3 different best fit approaches (parametric linear and non-linear, rank linear) to test for a relationship between $\mathrm{RR}$ and $\mathrm{MR}$ age or area for each biological response. This is a powerful approach in the absence of a priori knowledge about the biological response to MR protection, and provides new insights into the trajectories of change that we can expect for 2 target species. Although in all cases except one the best line relationship was curvilinear, the goodness of fit (as judged by the correlation coefficients) for the linear functions was only fractionally less than that for the non-linear functions. Thus, in terms of predicting or modelling biological responses, it is reasonable (at least for these 2 species and presumably other species with similar life-history characteristics and histories of extractive use) to employ a linear function, which is simple to fit and more easily understood and interpreted in a biological sense. The consistency of outcomes across both analyses (2 different RR indices and 3 different curve-fitting approaches) provides some degree of confidence in the interpretation of the quantifiable biological responses of blue cod and rock lobster to protection in NZ.

Direct comparison of the $\mathrm{RR}_{\text {recent }}$ values with the Hedges' $g$ values for species-specific responses revealed that 3 of 4 comparisons had positive slopes, and 2 of 4 comparisons were borderline statistically significant $(0.05>\mathrm{p}>0.04)$, suggesting that a linear relationship may exist between the 2 indices (Fig. 5). Given that both metrics are measuring the comparative biological response inside versus outside the MR in question, one might reasonably expect that a (linear) relationship exists between them. However, when the data for both species and both biological measures were combined, the relationship between $\mathrm{RR}_{\text {recent }}$ values and Hedges' $g$ values was positive but not statistically significant $(\mathrm{p}=0.206, \mathrm{n}=27$ ) or slightly negative when one point heavily influencing the plot $\left(\mathrm{RR}_{\text {recent }}\right.$ for rock lobster density at Cape Rodney to Okakari Point MR) was removed ( $\mathrm{p}=0.212$, $\mathrm{n}=26$ ) (Fig. 6). Thus, overall, there is little to indicate that a simple relationship exists between $R_{\text {recent }}$ values and Hedges' $g$ values. The reason for this is because the RR values are calculated as a simple function of mean size (density) inside versus outside each $\mathrm{MR}_{i}$ this ratio therefore is independent of any estimate of variance. In contrast, Hedges' $g$ is calculated not as a ratio, but as an estimate of mean size (density) inside minus mean size (density) outside the MR and then divided by a pooled variance estimate. The absence of a variance component in the RR statistic and the inclusion of a pooled variance component in the Hedges' $g$ statistic therefore generates 2 indices that are largely independent. From a biological perspective, it might be argued that the Hedges' $g$ statistic is in fact more meaningful than the RR statistic because its calculation includes the pooled variance estimate, thereby reflecting variability in size (density), which is known to be ecologically important. This apparent shortcoming of the RR index could be addressed by taking an approach that includes a variance component (e.g. Lajeunesse 2011).

\section{Use of the RR approach for assessing MR effectiveness}

Meta-analyses based on Hedges' $g$ are computationally difficult to conduct (e.g. Berman \& Parker 2002, Pande et al. 2008) when compared to other approaches such as response ratios; they require knowledge of sample variance that are often not reported in the literature, and they also include steps such as testing for differences in 'effect size', which, if significant, will preclude the completion of the meta-analysis. Whilst this latter step may be included in a RR analysis (e.g. Mosquera et al. 2000, present study), this is rarely done. 
Using a similar data set to that tested in the present study, Pande et al. (2008) observed significant differences in 'effect size' in their meta-analysis of blue cod and rock lobster size and density data. This meant that data from the different studies could not be combined to provide an overall significance estimate of the effect that all MRs had on these species. The significant differences in 'effect size' highlighted the significant differential contribution that individual MRs had on size and density of both species (although it was not possible to identify the nature of that response), and also precluded the completion of the analysis. In contrast, the RR analyses presented here are less constrained because our testing did not reveal a significant effect size, and have, as a consequence, permitted us to contribute significant new findings to the results of Pande et al. (2008). Nonetheless, we recommend that all RR studies should test for heterogeneity of the data set because such heterogeneity points to the differential effects across MRs, something that the researcher needs to appreciate.

The meta-analysis of Pande et al. (2008) did not identify either MR age or area as being significant factors explaining the biological responses of both species. The RR analyses presented here (Tables 2 \& 3) have identified MR age, but not MR area, as being important. The general concordance between the 2 analytical approaches is encouraging (notwithstanding the importance difference identified above) and suggests that the Hedges' statistic approach and the RR approach are equally valid. At the moment we cannot know if this statement holds true for only our NZ data set or for other data sets, but our comparison indicates that further exploration of this is worthwhile. Given that the RR approach does not require estimates of variance (which are often not provided in papers), there is a clear advantage to using this technique over the Hedges' statistic meta-analysis technique. However, the inclusion of a pooled variance estimate in the Hedges' $g$ index is likely to reflect biologically significant information that is lost in the present RR approach. Further investigation of an RR index that incorporates variance estimates is an approach that we recommend. Overall, there appears however to be no loss of information when using the RR compared to the Hedges' statistic metaanalysis, and the additional gain of information about the effect of MR age is important, as is the ease of use of the RR approach. In addition, we note that new developments will help resolve some of the common challenges faced when undertaking a meta-analysis (Lajeunesse 2011).

\section{CONCLUSIONS}

Our RR analyses of blue cod and rock lobster data from NZ MRs are consistent with a body of evidence that indicates that MRs are having consistent and positive effects on the density and size of protected species. While we could not identify an effect of MR area on biological responses, our results offer evidence that at the national level MRs of all sizes can generate positive biological responses.

We recommend that response ratio analysis should be used in preference to the Hedges' statistic metaanalysis because it is easier (less time-consuming) to employ, has fewer limitations, provides at least as much information as Hedges' statistic, and because its results are easier to interpret. Consistent with an increasing body of evidence, this RR analysis and the earlier meta-analysis based on Hedges' $g$ statistic (Pande et al. 2008) illustrate that MRs support larger and more abundant targeted species (in this case blue cod and rock lobster) than non-reserve areas. We suggest that the next important step in this line of investigation is to determine why and how individual MRs respond differently in their biological outcomesthat is, to test why a significant 'effect size' exists.

Acknowledgements. D. Diaz Guisado was supported by a $\mathrm{PhD}$ joint scholarship from CONICYT (Comisión Nacional de Investigación Científica y Tecnológica, Chile) and Victoria University of Wellington (New Zealand). This research was supported by funding from the New Zealand Department of Conservation and also from the Centre for Marine Environmental \& Economic Research at Victoria University of Wellington.

\section{LITERATURE CITED}

Adams DC, Gurevitch J, Rosenberg MS (1997) Resampling tests for meta-analysis of ecological data. Ecology 78: 1277-1283

Allison GW, Lubchenco J, Carr MH (1998) Marine reserves are necessary but not sufficient for marine conservation. Ecol Appl 8(Suppl):S79-S92

Arnqvist G, Wooster D (1995) Meta-analysis: synthesizing research findings in ecology and evolution. Trends Ecol Evol 10:236-240

Babcock RC, Kelly S, Shears NT, Walker JW, Willis TJ (1999) Changes in community structure in temperate marine reserves. Mar Ecol Prog Ser 189:125-134

Babcock RC, Shears NT, Alcala AC, Barrett NS and others (2010) Decadal trends in marine reserves reveal differential rates of change in direct and indirect effects. Proc Natl Acad Sci USA 107:18256-18261

Battershill CN, Murdoch RC, Grange KR, Singleton RJ, Aaron ES, Page MJ, Oliver MD (1993) A survey of the marine habitats and communities of Kapiti Island. Department of Conservation, Wellington

Berman NG, Parker RA (2002) Meta-analysis: neither quick 
nor easy. BMC Med Res Methodol 2:10 available at www.biomedcentral.com/1471-2288/2/10

Botsford LW, Micheli F, Hastings A (2003) Principles for the design of marine reserves. Ecol Appl 13(Suppl Mar Reserv):25-31

Botsford LW, Brumbaugh DR, Grimes C, Kellner JB and others (2009) Connectivity, sustainability, and yield: bridging the gap between conventional fisheries management and marine protected areas. Rev Fish Biol Fish 19:69-95

> Claudet J, Osenberg CW, Benedetti-Cecchi L, Domenici P and others (2008) Marine reserves: size and age do matter. Ecol Lett 11:481-489

Cole RG, Ayling AM, Creese RG (1990) Effects of marine reserve protection at Goat Island, northern New Zealand. NZ J Mar Freshw Res 24:197-210

Cole RG, Villouta E, Davidson RJ (2000) Direct evidence of limited dispersal of the reef fish Parapercis colias (Pinguipedidae) within a marine reserve and adjacent fished areas. Aquat Conserv 10:421-436

Côté IM, Mosquera I, Reynolds JD (2001) Effects of marine reserve characteristics on the protection of fish populations: a meta-analysis. J Fish Biol 59(Suppl A):178-189

Davidson RJ (1999) Tonga Marine Reserve, Abel Tasman, Nelson: subtidal biological baseline report. Survey and Monitoring Rep. No. 175a, Department of Conservation, Nelson

Davidson RJ (2001a) Changes in population parameters and behaviour of blue cod (Parapercis colias; Pinguipedidae) in Long Island-Kokomohua Marine Reserve, Marlborough Sounds, New Zealand. Aquat Conserv 11:417-435

Davidson RJ (2001b) Tonga Island Marine Reserve: proposed protocol for ongoing subtidal biological monitoring. Survey and Monitoring Rep No. 316, Department of Conservation, Nelson, www.doc.govt.nz/publications/ conservation/marine-and-coastal/marine-protected-areas/ marine-reserve-monitoring/tonga-island-proposed-monitoring-protocol/

Davidson RJ (2004) Long Island-Kokomohua Marine Reserve, Queen Charlotte Sound: 1992-2003. Survey and Monitoring Rep No. 343, Department of Conservation, Nelson, http://doc.govt.nz/upload/documents/conservation/marine-and-coastal/marine-protected-areas/ report-on-monitoring.pdf

Davidson RJ (2006) Horoirangi Marine Reserve, North Nelson rocky shore baseline biological report. Survey and Monitoring Rep No. 513, Department of Conservation, Nelson

Davidson RJ, Abel W (2002) Second sampling of Pohatu Marine Reserve, Flea Bay, Banks Peninsula. Survey and Monitoring Rep No. 443, Department of Conservation, DeVauchelle, www.doc.govt.nz/upload/documents/conservation/marine-and-coastal/marine-protected-areas/ report-on-monitoring-pohatu.pdf

Davidson RJ, Barrier R, Pande A (2001) Pohatu Marine Reserve baseline survey. Survey and Monitoring Rep No. 352, Department of Conservation, Canterbury, www. doc.govt.nz/upload/documents/conservation/marineand-coastal/marine-protected-areas/pohatu-report-onbaseline-survey.pdf

> Davidson RJ, Villouta E, Cole RG, Barrier RGF (2002) Effects of marine reserve protection on spiny lobster (Jasus edwardsii) abundance and size at Tonga Island Marine Reserve, New Zealand. Aquat Conserv 12:213-227

Davidson R, Richards L, Baxter A (2007) Tonga Island Marine Reserve, Abel Tasman National Park update of biological monitoring, 1993-2007. Survey and Monitoring Rep No. 484, Department of Conservation, Nelson, www.doc.govt.nz/upload/documents/conservation/ marine-and-coastal/marine-protected-areas/tongaisland-monitoring.pdf

Davidson RJ, Abel W, Richards LA (2009) Biological monitoring update 1992-2009: Long Island-Kokomohua Marine Reserve, Queen Charlotte Sound. Survey and Monitoring Rep No. 573, Department of Conservation, Nelson, www.doc.govt.nz/upload/documents/conservation/ marine-and-coastal/marine-protected-areas/Long \% 20 Island\%20update\%201992-2009.pdf

Department of Conservation and Ministry of Fisheries (2005) Marine protected areas policy and implementation plan. Department of Conservation, Ministry of Fisheries, Wellington

Egger M, Smith GD, Phillips AN (1997) Meta-analysis, principles and procedures. Brit Med J 315:1533-1537

Freeman DJ (2001) Te Tapuwae o Rongokako Marine Reserve baseline Survey Report. Technical Support Series report, Department of Conservation, Crisborne

Freeman DJ (2005) Reef fish monitoring, Te Tapuwae o Rongokako Marine Reserve. East Coast Hawke's Bay Conservancy. Technical Support Series No. 25, Department of Conservation, Gisborne, www.doc.govt.nz/upload/ documents/conservation/marine-and-coastal/marineprotected-areas/mmimp-reef-fish-monitoring.pdf

Freeman DJ (2008) The ecology of spiny lobsters (Jasus edwardsii) on fished and unfished reefs. PhD thesis, University of Auckland

Freeman DJ, Duffy CAJ (2003) Te Angiangi Marine Reserve reef fish monitoring 1995-2003. Technical Support Series No. 14, Department of Conservation, Hawke's Bay

Freeman DJ, MacDiarmid AB, Taylor RB (2009) Habitat patches that cross marine reserve boundaries: consequences for the lobster Jasus edwardsii. Mar Ecol Prog Ser 388:159-167

Gates S (2002) Review of methodology of quantitative reviews using meta-analysis in ecology. J Anim Ecol 71: $547-557$

Goldberg DE, Rajaniem T, Gurevitch J, Stewart-Oaten A (1999) Empirical approaches to quantifying interaction intensity: competition and facilitation along productivity gradients. Ecology 80:1118-1131

Guidetti P, Sala E (2007) Community-wide effects of marine reserves in the Mediterranean Sea. Mar Ecol Prog Ser 335:43-56

Haggitt T, Kelly S (2004) Cape Rodney to Okakari Point Marine Reserve Lobster Monitoring Programme: 2004 Survey. Department of Conservation, Auckland, www. doc.govt.nz/upload/documents/conservation/marineand-coastal/marine-protected-areas/report-on-lobstermonitoring.pdf

Halpern B (2003) The impact of marine reserves: Do reserves work and does reserve size matter? Ecol Appl 13(Suppl Mar Reserv):117-137

Halpern B, Warner RR (2002) Marine reserves have rapid and lasting effects. Ecol Lett 5:361-366

Halpern BS, Warner RR (2003) Matching marine reserve design to reserve objectives. Proc Biol Sci 270:1871-1878

> Hastings A, Botsford LW (2003) Comparing designs of marine reserves for fisheries and for biodiversity. Ecol Appl 13:65-70

Hedges LV, Olkin I (1985) Statistical methods for metaanalysis. Academic Press, San Diego, CA 
Hedges LV, Gurevitch J, Curtis PS (1999) The meta-analysis of response ratios in experimental ecology. Ecology 80: 1150-1156

Jones GP, Cole RG, Battershill CN (1992) Marine reserves: Do they work? In: Battershill CN, Schiel DR, Jones GP, Creese RG, MacDiarmid AB (eds) Proc 2nd Int Temp Reef Ecol Symp. Nat Inst of Water and Atm Res, Wellington, p 29-45

Kelly S (2001) Temporal variation in the movement of the spiny lobster Jasus edwardsii. Mar Freshw Res 52: 323-331

Kelly S, MacDiarmid AB (2003) Movement patterns of mature spiny lobsters, Jasus edwardsii, from a marine reserve. New Zeal Mar Fresh 37:149-158

Kelly S, Scott D, MacDiarmid AB, Babcock RC (2000) Spiny lobster, Jasus edwardsii, recovery in New Zealand marine reserves. Biol Conserv 92:359-369

Lajeunesse MJ (2011) On the meta-analysis of response ratios for studies with correlated and multi-group designs. Ecology 92:2049-2055

Lester SE, Halpern BS, Grorud-Colvert K, Lubchenco J and others (2009) Biological effects within no-take marine reserves: a global synthesis. Mar Ecol Prog Ser 384: $33-46$

MacDiarmid AB, Breen PA (1993) Spiny lobster population change in a marine reserve. In: Battershill CN, Schiel DR, Jones GP, Creese RG, MacDiarmid AB (eds) Proc 2nd Int Temp Reef Ecol Symp. Nat Inst of Water and Atm Res, Wellington, p 47-56

McCormick ML, Choat JH (1987) Estimating total abundance of a large temperate-reef fish using visual strip transects. Mar Biol 96:469-478

Micheli F, Halpern BS, Botsford LW, Warner RR (2004) Trajectories and correlates of community change in no-take marine reserves. Ecol Appl 14:1709-1723

Molloy PP, McLean IB, Côté IM (2009) Effects of marine reserve age on fish populations: a global meta-analysis. J Appl Ecol 46:743-751

Mosquera I, Côté IM, Jennings S, Reynolds JD (2000) Conservation benefits of marine reserves for fish populations. Anim Conserv 3:321-332

Munn A (2000) Lobster survey of Piopiotahi Marine Reserve, Milford Sound. Southland Conservancy, Department of Conservation, Wellington

Osenberg CW, Sarnelle O, Goldberg DE (1999) Special feature: meta-analysis in ecology: concepts, statistics, and applications. Ecology 80:1103-1104

Pande A (2001) Evaluating biological change in New Zealand marine reserves. PhD thesis, Victoria University

Editorial responsibility: Riccardo Cattaneo-Vietti, Genova, Italy of Wellington

Pande A, Gardner JPA (2009) A baseline biological survey of the proposed Taputeranga Marine Reserve (Wellington, New Zealand): spatial and temporal variability along a natural environmental gradient. Aquat Conserv Mar Freshw Ecol 19:237-248

Pande A, MacDiarmid AB, Smith PJ, Davidson RJ and others (2008) Marine reserves increase the abundance and size of blue cod and rock lobster. Mar Ecol Prog Ser 366: $147-158$

Roberts CM, Branch G, Bustamante RH, Castilla JC and others (2003) Application of ecological criteria in selecting marine reserves and developing reserve Networks. Ecol Appl 13:215-228

Samoilys MA, Martin-Smith KM, Giles BG, Cabrera B, Anticamara JA, Brunio EO, Vincent ACJ (2007) Effectiveness of five small Philippines' coral reef reserves for fish populations depends on site-specific factors, particularly enforcement history. Biol Conserv 136:584-601

Smith ED (2001) Lobster survey of Te Awaatu Marine Reserve, Doubtful Sound. Southland Conservancy, Department of Conservation, Wellington

Smith ED (2002) Lobster survey of Piopiotahi Marine Reserve, Milford Sound. Southland Conservancy, Department of Conservation, Te Anau, www.doc.govt.nz/ upload/documents/conservation/marine-and-coastal/ marine-protected-areas/piopiotahi-lobster-monitoringreport.pdf

Stewart RA, MacDiarmid AB (2003) A Survey of Kaimoana at Kapiti Island 1999 and 2000. NIWA Project: DOC 03402. Department of Conservation, Nelson, www.doc. govt.nz/upload/documents/conservation/marine-andcoastal/marine-protected-areas/survey-of-kaimoana.pdf

Struthers C (2004) Monitoring of blue cod (Parapercis colias) at Kapiti Marine Reserve, New Zealand: a comparison of survey methodologies. MSc thesis, Victoria University of Wellington

Taylor RB, Anderson MJ, Egli D, Willis TJ (2003) Cape Rodney to Okakari Point Marine Reserve fish monitoring 2003: final report. Department of Conservation, Auckland, www.doc.govt.nz/upload/documents/conservation/ marine-and-coastal/marine-protected-areas/report-onfish-monitoring.pdf

Willans M (2003) Lobster survey, Te Awaatu (The Gut) Marine Reserve, Doubtful Sound. Southland Conservancy, Department of Conservation, Wellington. http:// doc.govt.nz/upload/documents/conservation/marineand-coastal/marine-protected-areas/te-awaatu-lobstermonitoring-report.pdf

Submitted: June 8, 2011; Accepted: October 31, 2011

Proofs received from author(s): January 13, 2012 